\title{
Our Horticultural Heritage from the Americas: Introduction to the Workshop
}

\author{
Chad Finn \\ U.S. Department of Agriculture-Agricultural Research Service, Northwest Center for Small Fruit Research, \\ Corvallis, OR 97330
}

Too often as we look at the origins of the important food crops, we are overwhelmed with the large number of crops with origins in Eurasia and Africa and forget the valuable contributions that crops of the pre-Columbian Americas have made to our diet. The "Three Sisters" - maize, beans, and squash — played an integral role in native North American culture. The berries represented in Rubus (blackberry, raspberry), Vaccinium (huckleberry, blueberry, cranberry), Ribes (currants and gooseberries), Fragaria (strawberry), and others were regionally abundant in North America. Perhaps because of their abundance, they were never domesticated. South American culture relied on a wide variety of "root" crops, such as Oxalis tuberosa Mol., Ullucus tuberosus Caldas, Tropaeolum tuberosum R. \& P., and the critically important potato (Solanum sp.). Chiles (Capsicum sp.) were worshiped and valued for their contribution to the diet of early North Americans. The Chilean strawberry ( $F$. chiloensis L.) has been important in South American Andean culture from historic to present times and played a critical role in the development of the cultivated strawberry (Fragaria $\times$ ananassa Duch.).

For this workshop, two South American crops, potato (Solanum sp.) and strawberry ( $F$. chiloensis), and three North American crops, chiles (Capsicum sp.), squash (Cucurbita sp.), and maize (Zea mays L.), were chosen as examples of the role pre-Columbian crops play in our diet.

"Chiles: A Gift from a Fiery God" by Paul Bosland, reviews the botanical and cultural origins of chiles. He makes the case that chiles were the first plants to be domesticated in the Western Hemisphere. Despite the fact that historians and archeologists have often ignored the importance of chiles in favor of the crops that provide more of the

Received for publication 16 July 1998. Accepted for publication 1 Dec. 1998. The cost of publishing this paper was defrayed in part by the payment of page charges. Under postal regulations, this paper therefore must be hereby marked advertisement solely to indicate this fact. caloric intake for native peoples, chiles were important as a seasoning and for medicinal and religious uses. One of the most fascinating points made is the rapidity with which chiles became an integral part of diets around the world after they were brought to Europe by Columbus and other explorers. As we eat fiery Sichuan and Thai dishes in Asian restaurants, aromatic curry in Indian restaurants, pungent Ethiopian food, and traditional Hungarian food with paprika, we are enjoying traditional foods that are only 300 to 400 years old, as they were not developed until after chiles were brought back by explorers to the Old World where they could then spread across the Eurasian and African continents. Chiles have also played an important role as medicinal plants. Today, pharmacies sell many products, primarily topical analgesics, with chiles as ingredients. The critical role that New Mexico State Univ. played in developing a milder chile that was suitable for mass consumption, subsequently called the New Mexican pod type or "Anaheim," is presented. This type of chile has been the industry's mainstay for much of this century; however, there is a resurgent interest in all types of chiles.

"Our Southern Strawberry Heritage: Fragaria chiloensis of Chile" by Jim Hancock introduces us to the origins of the cultivated octoploid strawberry. The primary strawberry of commercial interest is the octoploid $F$. ×ananassa, a hybrid of the octoploid species $F$. chiloensis and $F$. virginiana Duch. The evolutionary origin of the octoploid strawberries is clouded; however, genetic analysis would suggest that the original octoploid arose in East Asia and then spread across the Bering Strait to North America and eventually South America. While strawberries were collected by North American native people, they were never domesticated as they were by the Mapuche in South America $\approx 2000$ years ago. Despite our current preference, the large, white-fruited types seem to have been equally preferred to red types by the native South Americans. Fragaria chiloensis culture has largely disappeared, being replaced by North American cultivars of $F$. $\times$ ananassa, but there are still small plantings of these land races and a 
concerted effort to collect these types is recommended. Finally, Hancock suggests that a much greater utilization of $F$. chiloensis is warranted because of its superior characteristics gained through phenotypic selection of the best clones over many years by native people.

Maize has historically been an important source of calories and nutrients. This, its adaptability to a wide number of environments, and its versatility (it can be harvested as baby ears, as a green vegetable, and as a dry grain) have made it an extremely valuable and important crop since its domestication. William Tracy, in "Vegetable Uses of Maize in Pre-Columbian America," gives an overview of the development of maize as a crop and native peoples' development of it as an important food source. In addition to its value in and of itself, the nutritional value added by lime or wood ash processing made it especially valuable in preventing nutritional diseases in native cultures. While not commonly considered as a typical product, corn smut was valued as a cooked and preserved product in most cultures as well. Most of the historical uses of maize are still mainstays in our diet.

Charles Brown, in "A Native American Technology Transfer: The Diffusion of Potato," lays out the historical development of one of the most important food crops. While entirely of South American origin, potato played a critical role in the large population increases and development of Europe in the middle of this millennium. Surprisingly, while the Spanish knew of the value of the potato in South America, it took a long time for its value to be recognized in Europe, in large part because many of the first potatoes brought to Europe did not produce tubers under daylength regimes very different from those in the Andes. Because of the potato's long association with civilization in South America, many different types were developed, and even today farmers will often grow one type to sell and another for home use. The processing of bitter types, either through freezing or through cooking with clay to remove the alkaloids, is an excellent example of the early use of processing technology.

Potatoes and maize were wonderfully diverse dietary mainstays of historical cultures and of society today. Strawberries have provided delight and variety in our diet. Chiles have not only become a major flavoring and food source throughout the world but have contributed mightily to our pharmacies. As we move forward as plant breeders and scientists, these historically important crops, with their extremely valuable, diverse germplasm, will continue to be critical for our food supply into the new millennium. 